\title{
Helical computed tomographic-dacryocystography in adult pet dwarf rabbits: procedure and normal appearance
}

\author{
Helicale computertomografie - dacryocystografie bij volwassen dwergkonijnen: \\ procedure en normaal uitzicht
}

\author{
${ }^{1} \mathrm{~J}$. Fritz, ${ }^{2 *} \mathrm{H}$. Gaillot, ${ }^{2}$ Y. Ruel
}

${ }^{1}$ Department of diagnostic imaging, center of veterinary specialists Azurvet, Saint-Laurent-du-Var, France

${ }^{2}$ Department of diagnostic imaging, ADVETIA Veterinary Referral Hospital, Vélizy-Villacoublay, France

gaillot@advetia.fr

\section{$\Lambda_{\text {bstract }}$}

Partial or complete nasolacrimal drainage system (NLDS) occlusion is a common clinical concern in rabbits. It can be assumed that computed tomographic-dacryocystography (CTDCG) might be an efficient technique in this indication. In this prospective study, the technique of CT-DCG and the appearance of the NLDS in eight healthy rabbits on CT-DCG images are described. The quality of visualization of bony structures adjacent to the NLDS was good on pre-contrast computed tomographic images. The bony lacrimal canal had a smooth contour, a regular diameter, and its mean dimensions are provided. CT-DCG technique was easy to perform and offered a good visualization of the NLDS including anatomical narrowings and bendings. CT-DCG is a minimally invasive and informative technique for evaluating the NLDS in rabbits. Its diagnostic usefulness in exploring nasolacrimal diseases remains to be specified in this species.

\section{SAMENVATTING}

Gedeeltelijke of volledige occlusie van het nasolacrimale drainagesysteem (NLDS) is een veelvoorkomend klinisch probleem bij konijnen. Computertomografische dacryocystografie (CTDCG) kan een efficiënte techniek zijn voor de behandeling van deze indicatie. In deze prospectieve studie worden de CT-DCG-techniek en het uitzicht van de CT-DCG-beelden van het NLDS bij acht gezonde konijnen beschreven. De kwaliteit van de visualisatie van osseuze structuren in de proximiteit van het NLDS was goed op de pre-contrast computertomografische beelden. Het beenderige lacrimale kanaal had een gladde aflijning, een gelijkmatige diameter en de gemiddelde waarden worden in de voorliggende studie weergegeven. De CT-DCG techniek was makkelijk uitvoerbaar en kon het NLDS goed in beeld brengen, inclusief anatomische vernauwingen en bochten. CT-DCH is een minimaal invasieve en informatieve techniek voor de evaluatie van het NLDS bij konijnen. Zijn diagnostische meerwaarde in het onderzoek naar nasolacrimale aandoeningen dient nog verder gespecificeerd te worden bij deze diersoort.

\section{INTRODUCTION}

Helical computed tomography is commonly used to assess the bony lacrimal canal and the nasolacrimal drainage system (NLDS) in human medicine (Janssen et al., 2001; Freitag et al., 2002). CT without injection of a contrast medium (non-contrast CT) is useful to evaluate the bony structures surrounding the NLDS while computed tomographic-dacryocystography (CT-
DCG) provides CT images after nasolacrimal injection of a iodine-based contrast medium and is well suited for an accurate visualization of the NLDS (Ansari et al., 2005). Magnetic resonance imaging dacryocystography is also used in human patients. This technique has also been experimented in a feasibility study in horse cadavers (Manso-Diaz et al., 2019).

In veterinary medicine, protocols and normal images of CT-DCG have been described in dogs (Rached 


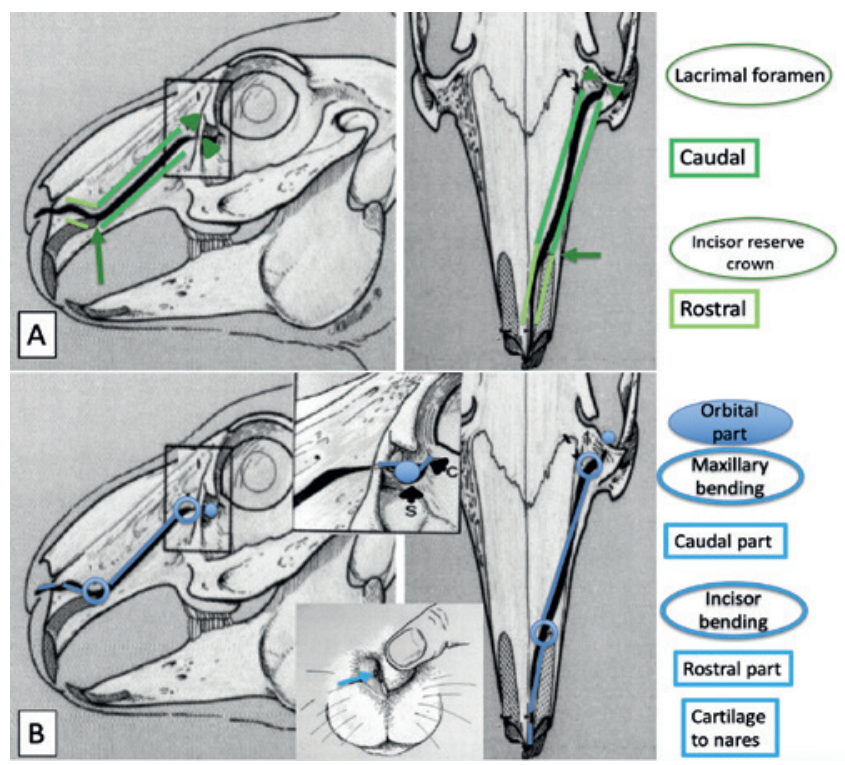

Figure 1. Anatomy of the lacrimal canal and NLDS in rabbits. A. Lateral and dorsal views of the lacrimal canal, showing the lacrimal foramen (arrowheads), the caudal portion of the lacrimal canal (dark green lines), the major incisor reserve crown (dark green arrows), and the rostral portion of the lacrimal canal (light green lines). B. Lateral and dorsal views of the NLDS, with top insert showing a close-up of the orbital segment of the NLDS, and bottom insert showing the nasal meatus (meatus has been magnified for didactic purposes). The top insert shows the canaliculus $(C)$ and the lacrimal sac (S). The two bends of the lacrimal duct, the maxillary and the incisor bend are pointed out by blue circles. The widest segment of the lacrimal duct runs into the caudal/straight segment of the lacrimal canal from the maxillary bend to the incisor bend. The rostral segment of the lacrimal duct extends into the rostral/tortuous portion of the lacrimal canal (tubular segment of the duct) from the incisor bend to the nasal cartilage where the lacrimal canal terminates. The rostral most segment of the lacrimal duct (membranous segment of the duct) exits the lacrimal canal and extends to the nasal meatus (Drawings: Dr Kristina Burling, with courtesy).

et al., 2011) and cats (Nöller et al., 2006; Schlueter et al., 2009). Diagnostic usefulness of CT-DCG in selected patients has been illustrated in the dog, horse and donkey occasionally (Nykamp et al., 2004 ; Cleary et al., 2011). In rabbits, assessment of the NLDS using radiographic dacryocystography has been described (Marini et al., 1996), but to the authors' knowledge, protocols and normal images of CT-DCG have not been published in this species yet.

Computed tomography is more and more widely used in exotic mammals, particularly in pet rabbits (Capello et al., 2008). Latest generation CT machines produce high-resolution images that are particularly well suited to small-sized animals as they offer very thin slices and large image matrices. Additionally, current workstations provide reconstruction capabilities such as multiplanar reconstruction, maximum intensity projection (MIP) reconstruction and threedimensional (3D) post-processing that tremendously facilitate the assessment of small-sized and complex anatomical regions such as the skull (Fishman et al., 2006).

Ocular discharge secondary to partial or complete NLDS occlusion is a common clinical concern in pet rabbits. An NLDS occlusion is considered in case of difficult or unsuccessful nasolacrimal flushing. A recent endoscopic and histopathologic study in rabbits with experimentally-induced dacryocystitis has shown that chronic inflammation can be a cause of NLDS obstruction (Liu et al., 2018). The authors suspected that, as demonstrated in humans, CT-DCG might be an efficient technique to confirm nasolacrimal occlusion and to identify the underlying cause in companion rabbits (Marini et al., 1996; Freitag et al., 2002; Ansari et al., 2005; Rehorek et al., 2011).

Rabbits are highly susceptible to dental diseases that are considered by many authors as the main cause of nasolacrimal occlusion (Burling et al., 1991; Capello et al., 2008; Florin et al., 2009 ; Van Caelenberg et al., 2011a; Artiles et al., 2020). Published studies on $\mathrm{CT}$ in rabbits have been mostly focused on teeth and surrounding bony structures (Van Caelenberg et al., 2010 and 2011a; De Rycke et al., 2012). These studies are limited to non-contrast CT and do not thoroughly describe the examination procedure and the normal appearance of the NLDS.

Burling et al. (1991) have described the normal anatomy of NLDS in rabbits using gross dissection, latex casting, dacryocystorhinography and histology. The lacrimal punctum is the unique caudal aperture of the NLDS and is located at the inner surface of the lower eyelid. From the punctum, the canaliculus runs rostro-medially up to a focal dilation of the NLDS, the lacrimal sac. Rostrally to the sac, the lacrimal duct passes through the lacrimal foramen delineated by the lacrimal and maxillary bones and enters the caudal portion of the lacrimal canal.

The caudal portion of the lacrimal canal is wide and straight. It runs obliquely into the maxillary bone with a caudo-dorso-lateral to rostro-ventro-medial direction. It harbors the widest segment of the lacrimal duct and ends up at the caudal aspect of the major maxillary incisor tooth. The rostral portion of the lacrimal canal is tortuous. It curves medially and ventrally to the major incisor tooth reserve crown, extends rostrally and terminates caudally to the nasal cartilage.

The lacrimal duct exits the rostral portion of the lacrimal canal and passes through the nasal cartilage before terminating at the nasal meatus. The nasal meatus is located a few millimeters caudal to the mucocutaneous junction of the nasal vestibule. The shape of the NLDS and lacrimal canal and their different segments are shown in Figure 1.

The aim of this study was to describe the normal features of the lacrimal canal using non-contrast CT, 
to propose a CT-DCG protocol and to describe the normal features of the NLDS on CT-DCG in pet rabbits.

\section{MATERIALS AND METHODS}

\section{Animals}

This study was a prospective descriptive design. It was conducted from november 2010 to april 2012. The study protocol was approved by the VetAgro Sup Animal Care and Use Committee (Comité d'éthique Jacques Bonnod - Institut d'enseignement supérieur et de recherche en alimentation, santé animale, sciences agronomiques et de l'environnement, Marcy L'Etoile, France). Animal owners provided signed informed consent.

To be enrolled in the study, rabbits had to be owned by a member of ADVETIA clinical staff, be healthy, have a normal clinical examination, undergo a noncontrast CT of the head as a screening procedure aimed at detecting early stage of subclinical dental disease with no anomaly.

The rabbits were sedated with midazolam $(0.5 \mathrm{mg})$ $\mathrm{kg}, \mathrm{IM})$ and anesthetized by inhalation of isoflurane ( 2 to $3 \%$ ) and oxygen. In all rabbits, CT-DCG was performed following non-contrast CT while prolonging general anesthesia for 10 to 15 minutes.

\section{CT protocol}

CT examinations were all performed at ADVETIA Veterinary Referral Hospital, using a spiral four-slices CT scanner (Aquilion Toshiba).

All rabbits underwent a CT examination of the head including a bone algorithm acquisition before and after injection of iodinated contrast medium into the NLDS.

Pre- and post-contrast helical acquisitions were obtained with exposure parameters of $120 \mathrm{kV}$ and $100 \mathrm{~mA}$, a slice thickness of $0.5 \mathrm{~mm}$, a reconstruction interval of $0.3 \mathrm{~mm}$. All images were reconstructed using a $512 \times 512$ matrix, a slice thickness of $0.5 \mathrm{~mm}$, and both bone and soft tissue algorithms. Only bonereconstructed images were used in this study.

The rabbits were symmetrically positioned in sternal recumbency on the scanning table for transverse CT images acquisition.

Before the acquisition of CT-DCG images, both right and left lacrimal punctum were cannulated.

The distal third of a $26 \mathrm{G}$ plastic irrigating cannula (Portex Irrigating Cannula: external diameter of 0.46 $\mathrm{mm}$, length of $32 \mathrm{~mm}$ - Smiths Medical International Ltd), that was previously filled with contrast medium, was inserted through the lacrimal punctum.

Half-strength water-soluble iodinated contrast medium (iohexol - Omnipaque $300 \mathrm{mgI} / \mathrm{mL}$ - GE Healthcare SAS France) was gently injected in each NLDS while a mild digital pressure was applied over the rostral aspect of the lower eyelid in order to prevent lacrimal sac overdistension and rupture (Figure 2). The range of injected volume was 0.5 to $1 \mathrm{ml}$. The injection was stopped once contrast medium was visualized at the nares. The rabbits were scanned immediately after bilateral injection.

All images were evaluated by a board-certified radiologist (HG or YR) to confirm their diagnostic quality.

\section{CT measurements}

Stored CT images were collected and evaluated using a workstation equipped with a DICOM viewer (OsiriX v.3.9.4 64-bit for Macintosh) by three observers (JF, HG, YR). A consensus between the observers was reached concerning the quality of the lacrimal canal visualization, the degree of the NLDS filling and the measurements.

The bony lacrimal canal was observed using a bone-window setting ( $850 \mathrm{HU} / 3500 \mathrm{HU}$ - level /width) but the observers were allowed to modify the settings in order to optimize canal wall visualization. The visualization of the wall of the canal was graded as: "bad" (no wall visualized), "poor" (large wall interruptions), "fair" (focal wall interruptions) and "good" (no wall interruption). The presence of gas in any portion of the NLDS was recorded.

Multiplanar reconstruction (MPR) was used to de-

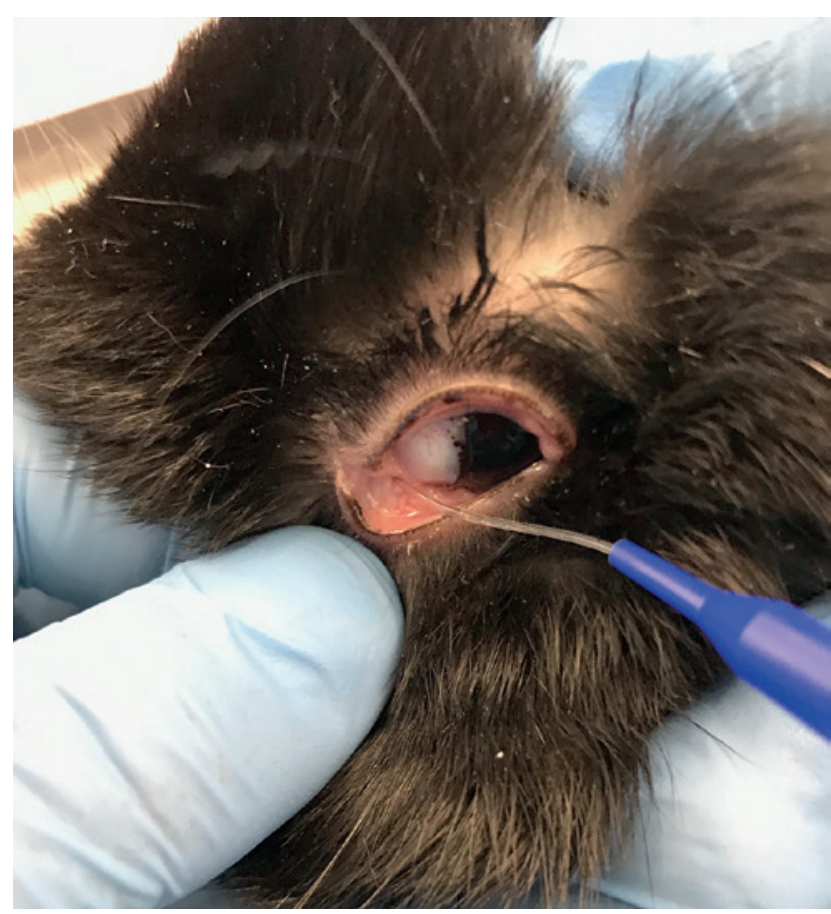

Figure 2. Technique of injection for CT-DCG showing the procedure of catheterization of the lacrimal punctum and injection while a mild digital pressure is applied over the rostral aspect of the lower eyelid in order to prevent lacrimal sac overdistension and rupture. 


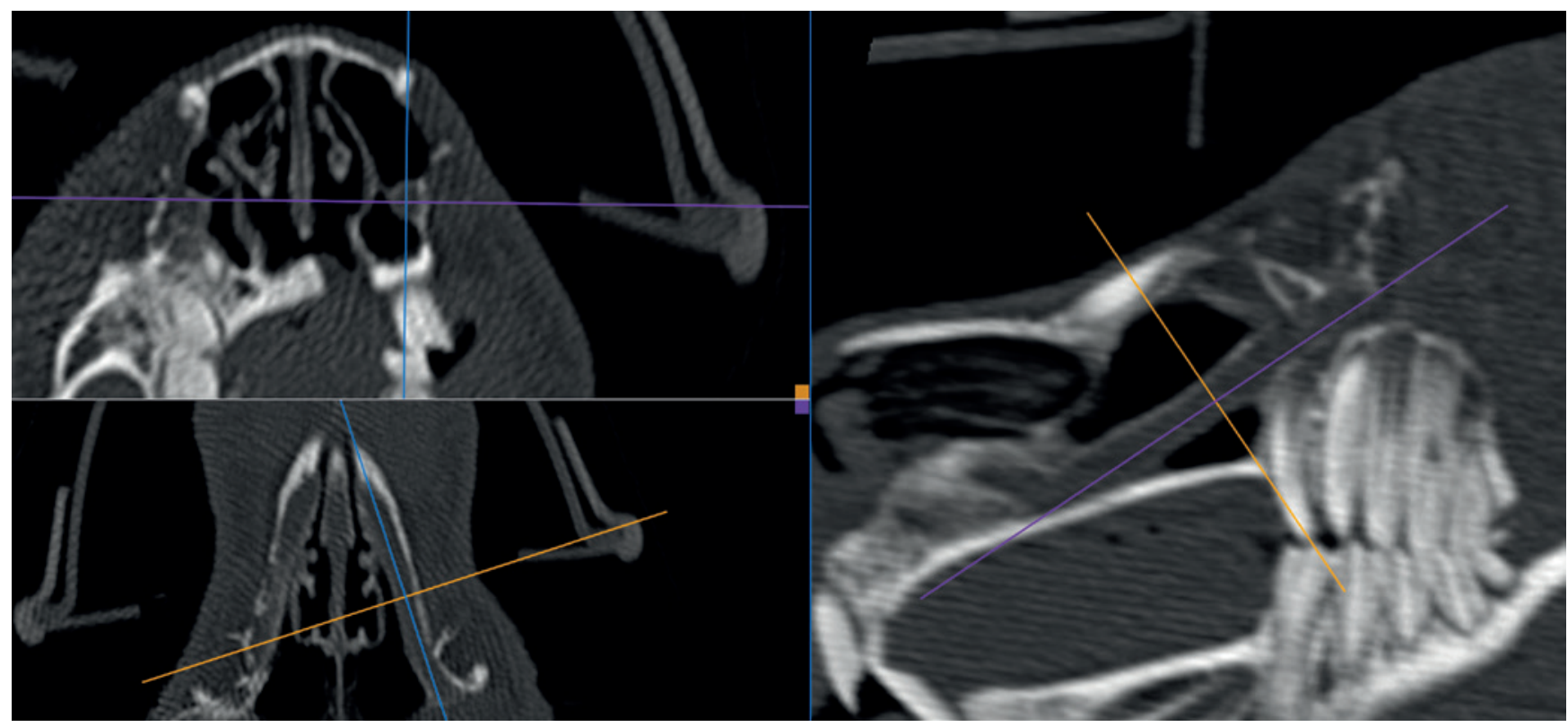

Figure 3. Non contrast CT MPR reconstruction of the left lacrimal canal in a rabbit.

scribe the shape and direction of the lacrimal canal and to obtain measurements (Figure 3).

In all rabbits, right and left lacrimal canals were separately assessed on dedicated reconstructed images as they run in different planes.

Caudal and rostral segments of the lacrimal canal were defined as shown in Figure 1. The caudal segment is the longest and straight segment running from the lacrimal foramen to the incisor reserve crown. The rostral segment is a tortuous segment running between the incisor reserve crown and the nasal cartilage.

MPR oblique sagittal and oblique dorsal planes showing the caudal/straight portion of the lacrimal canal were selected to separately display the right and the left lacrimal canals along their long axis, and to provide accurate transverse views of each canal. Dorso-ventral (DV) and latero-lateral (LL) inner diameters were measured at the rostral aspect, midlength and caudal aspect of the caudal/straight portion of each lacrimal canal on transverse reconstructed images of the head. The length of the caudal/straight portion of the lacrimal canal was also recorded, using oblique sagittal reconstructed images of each canal.

The angle between the caudal/straight portion of the lacrimal canal and the hard palate was also measured (Figure 4).

Inner diameters (DV and LL) of the rostral/tortuous portion of the lacrimal canal (at its caudal aspect, mid-length and rostral aspect) were measured on the same transverse MPR images for both sides as the right and left rostral portions run parallel to each other.

Window level /width of $1500 \mathrm{HU} / 5000 \mathrm{HU}$ were used to assess the contrast medium distribution in the NLDS and to measure the lacrimal duct diameter. The observers were allowed to modify the window settings for optimization.

The filling of each segment of the NLDS with the contrast medium was graded using the four-point scale as previously proposed in dogs (Rached et al., 2011): grade $0=$ no contrast medium visualized into the NLDS; grade $1=$ contrast medium barely visible, limiting assessment of the ductal lumen; grade $2=$ duct clearly visualized with sufficient amount of contrast medium, focal filling defect is possible (gas bubble); grade $3=$ duct fully visualized with no filling defect.

The NLDS was divided into six segments defined as follows: A. orbital segment with an attempt to differentiate the canaliculus, the lacrimal sac and the duct into the lacrimal foramen, B. caudal maxillary bend (narrowing and bending of the duct into the maxillary bone), C. straight segment (duct into the caudal/

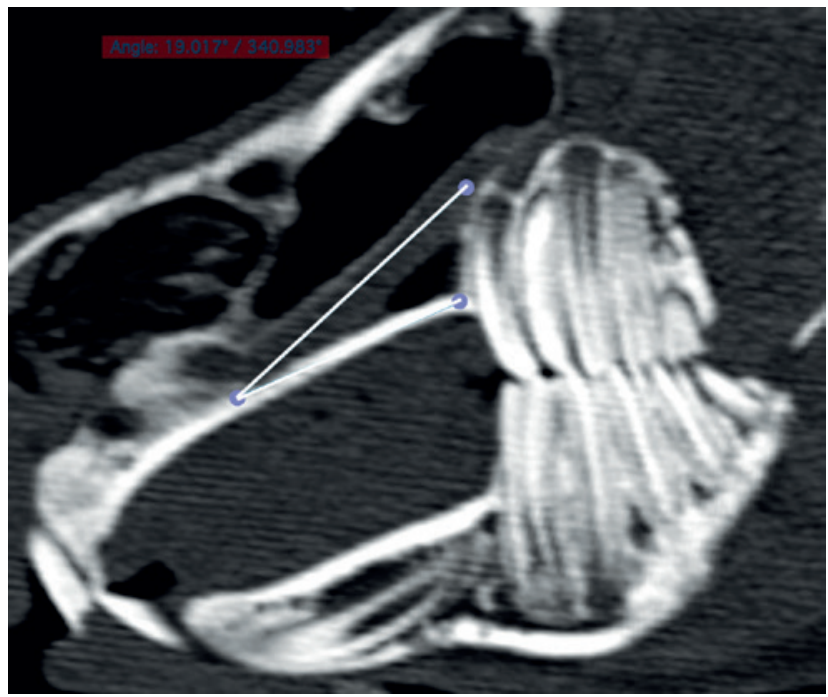

Figure 4. Measurement of the angle between the caudal/ straight portion of the lacrimal canal and the hard palate using non contrast $\mathrm{CT}$. 
straight portion of the lacrimal canal), D. rostral incisor bend (narrowing and bending of the duct medial to the tip of the reserve crown of the major incisor tooth), E. rostral tubular segment (duct into the rostral/tortuous portion of the lacrimal canal), F. rostral membranous segment (duct rostral to the lacrimal canal extending in the submucosal tissues and emerging in the nasal cavity caudal to the nostrils) (Figure 5) .

Three-dimensional maximum-intensity-projection (MIP) reconstructions were generated from CT-DCG images to provide an overview of the contrast filled NLDS. MPR images were obtained to measure the diameters of the canaliculus, the lacrimal sac and the different segments of the duct (Figure 6). Planes orientation was modified as required in order to obtain accurate transverse view of each segment of the duct for measurements.

The following measurements of the contrast medium-filled NLDS were obtained: maximum diameters of the canaliculus, lacrimal sac and duct into the foramen (segment A); minimum diameter of the caudal maxillary bend of the duct (segment B); DV and LL diameters of the straight segment of the duct at its caudal aspect, mid-length and rostral aspect (segment C); minimum diameter of the rostral incisor bend of the duct (segment D); DV and LL diameters of the rostral tubular segment of the duct (segment E); maximum diameter of the rostral membranous segment of the duct (segment F). The length of the caudal/straight portion of the NLDS (segment C) was recorded on CT-DCG images as the distance between the sites of measurement of the rostral and caudal diameters.

The appearance of the mucosal surface was recorded as smooth or irregular.

\section{Data presentation and statistical analysis}

The dimensions of the lacrimal canals and the contrast medium-filled NLDS are presented as mean val-

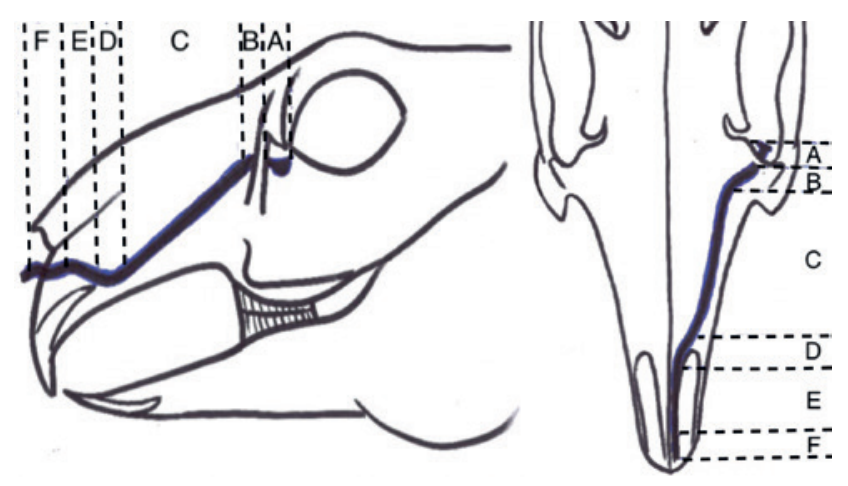

Figure 5. Diagram of the rabbit NLDS showing the six segments studied. A. Orbital segment (canaliculus, lacrimal sac and duct into the foramen). B. Caudal maxillary bend. $C$. Straight segment in the caudal/straight portion of the lacrimal canal. D. Rostral incisor bend. E. Rostral tubular segment in the rostral/tortuous portion of the lacrimal canal. F. Rostral membranous segment.
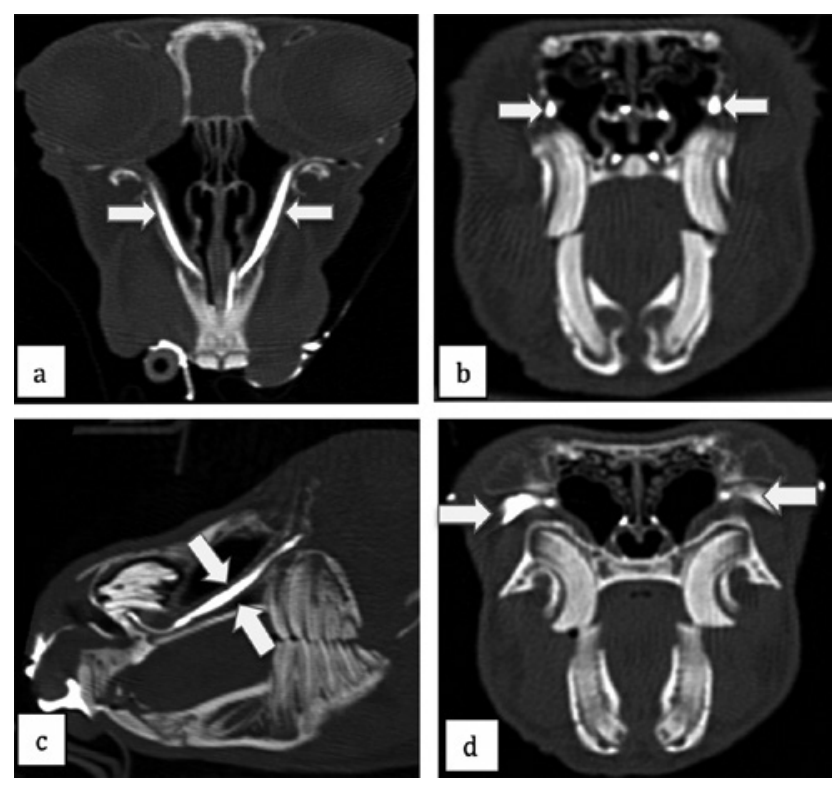

Figure 6. MPR reconstruction of contrast filled NLDS (white arrows) of a rabbit. A. Dorsal oblique plane providing a dorsal view of the straight segments of the right and left NLDS (segments $C$ ). B. Transverse view of the straight segment of the right and left NLDS at the level of the first jugal tooth (segments $C$ ). C. Oblique parasagittal plane providing a sagittal view of the left NLDS (segment C). D. Transverse view of the head at the level of the second maxillary jugal teeth showing both lacrimal sacs (incompletely visualized) and both ducts as they enter the lacrimal foramen (segment $A$ ).

ues and standard deviation in Tables 1 and 2. Spearman's tests were obtained in order to evaluate a potential correlation between dimensions of NLDS and rabbit's weight and age.

\section{RESULTS}

Eight rabbits with normal incisor teeth, jugal teeth and bony structures of the head on non-contrast CT images were selected for the study and provided 16 lacrimal apparatus to be assessed using CT-DCG. They were all dwarf rabbits with an age ranging from two to six years (mean age $2.9+/-1.4$ years) and a weight ranging from 1.5 to $3 \mathrm{~kg}$ (mean $2.2+/-0.5 \mathrm{~kg}$ ). There were four males and four females.

Non-contrast CT: lacrimal canal

\section{Visualization}

Visualization of the caudal portion of the lacrimal canal was fair or good in all rabbits (16/16 canals).

The rostral portion of the lacrimal canal was well or fairly visualized in 14/16 canals. Visualization was poor in 2/16 canals (both in the same rabbit), preventing measurements. 
Table 1. Measurements of the caudal and rostral segments of the lacrimal canal (mean \pm SD).

\begin{tabular}{lcccc}
\hline & Caudal straight segment & Rostral tortuous segment \\
\hline Length $(\mathrm{mm})$ & $16.5 \pm 1.6$ & & & \\
Angle with hard palate $\left(^{\circ}\right)$ & $23.6 \pm 2.9$ & & $\mathrm{DV}$ & $\mathrm{DL}$ \\
Diameter DV $(\mathrm{mm})$ and LL $(\mathrm{mm})$ & $\mathrm{DV}$ & $1.6 \pm 0.2$ & $1.6 \pm 0.4$ & $1.4 \pm 0.4$ \\
${ }^{\circ}$ caudal aspect & $1.4 \pm 0.3$ & $1.5 \pm 0.2$ & $1.5 \pm 0.3$ & $1.3 \pm 0.3$ \\
${ }^{\circ}$ middle-length & $1.7 \pm 0.2$ & $1.8 \pm 0.4$ & $1.7 \pm 0.4$ & $1.4 \pm 0.4$ \\
${ }^{\circ}$ rostral aspect & $2.1 \pm 0.3$ & & & \\
\end{tabular}

\section{Presence of gas}

Gas was observed in 4/16 NLDS. It was present in both the lacrimal sac and the caudal segment of the duct in $2 / 4$, in the caudal segment alone in $1 / 4$, and in both the caudal segment and the rostral segment 1/4.

\section{Shape}

The caudal portion of 13/16 lacrimal canals appeared straight with smooth borders. In six rabbits, both right and left canals had a straight caudal segment. In one rabbit, the caudal segment of the right canal was straight, and the caudal segment of the left canal was mildly curved medially. In one rabbit, the caudal segments of both canals were mildly curved medially. The rostral portion of all lacrimal canals appeared mildly tortuous with smooth borders.

\section{Measurements}

The measurements of the caudal and the cranial portions of the lacrimal canal are presented in Table 1.

\section{CT-Dacryocystography: nasolacrimal drainage system}

\section{Shape}

All six anatomical segments of the NLDS previously described were identified on CT-DCG images in all rabbits. The shape of the different segments of the NLDS (lacrimal sac, caudal maxillary bend, caudal straight segment, rostral incisor bend and rostral tortuous segment of the duct) was easily recognized and appeared symmetrical in all rabbits (16 NLDS). The mucosal surface of the duct was smooth in all NLDS (16/16).

\section{Visualization}

The visualization of the orbital segment of the NLDS (segment A) was considered poor (grade 0 or 1) and did not allow measurements when the cannula was left in place (7NLDS/16). Conversely, the visualization was considered good (grade 2 or 3 ) and allowed measurements when the cannula had been removed just before scanning $(9 / 16)$.

The visualization of the caudal maxillary bend, straight segment, rostral incisor bend, rostral tubular segment and rostral membranous segment of the lacrimal duct (segments B to F) was good (grade 2 or 3 ) in all NLDS (16/16), allowing accurate measurements.

\section{Presence of gas}

A mild amount of gas was observed in 4/16 NLDS. Gas was located in the lacrimal sac in all 4 NLDS and was also noticed in the straight segment of the duct in $1 / 4$ NLDS.

\section{Measurements}

The dimensions of the different segments of the contrast filled NLDS are presented in Table 2. There was no significant correlation between any of the measurements and the age or weight of the rabbits.

\section{DISCUSSION}

This study shows that non-contrast CT with bone algorithm acquisition enables the visualization of the lacrimal canal in rabbits. It has regular smooth borders along its caudal straight segment and its rostral mildly tortuous segment and its dimensions are presented. Gas can be present in the canal of ocular disease-free rabbits. In this study, it is also shown that the CT-dacryocystography technique used, including bilateral half- strength water-soluble iodinated contrast medium through a previously flushed plastic cannula and immediate CT with bone algorithm acquisition, enables a good visualization of all of the NLDS segments when the cannula is removed before scanning. All of the segments were easily recognized, symmetrical, with smooth mucosal surface, and its dimensions are provided. In previous studies, the CT-anatomy of a rabbit's head and the viewing of the lacrimal canal using CT (Van Calenberg et al., 2010), micro-computed tomography (De Rycke et al., 2012) 
and low-field magnetic resonance (Van Caelenberg et al., 2011b) have been described. In the present study, non-contrast CT identified very little to no variation in lacrimal canal shape, course and dimensions between rabbits. To the authors' knowledge, this is the first study to describe the CT-anatomy of the lacrimal canal and provide measurement references in healthy dwarf rabbits.

The course and the shape of the lacrimal duct have already been described in two studies: one using dacryocystorhinography, latex casting and gross dissection (Burling et al., 1991), and the other one using dacryocystorhinography and gross dissection (Marini et al., 1996). Using CT-DCG, in the present study, a shape and a course of le NLDS were observed that were similar to those previously described, including a tubular portion with anatomical narrowings and bendings, and a caudal straight segment (segment C) exhibiting a progressive enlargement from caudal to cranial up to the incisor bending (segment D). The diameter of the lacrimal duct measured in the present study was quite different from the duct diameter published in the two studies mentioned above. The differences in duct diameter are probably due to a range of factors including the used imaging modality (radiography versus CT in the present study), the selected populations (New Zealand white rabbits versus smaller dwarf rabbits in the present study) and the provided diameters (unique mean diameter versus separate DV and LL dimensions in the present study).

The length of the straight portion of the NLDS (segment C) measured in the present study is smaller than the length published in Burling's study that is 26.4+/-2.3mm (Burling et al., 1991). This discrepancy might be due to the differences in size and head conformity of the rabbits selected in both studies, and to the methods of measurement that were also different. In the present study, direct linear measures were taken of the duct length on reconstructed CT images while Burling et al. used a trigonometric method for calculating the length of the duct from linear measures taken on radiographs (dacryocystorhinography). The radiography might also have induced an imprecision in measurement due to the magnification inherent to this imaging technique.

In the present study, lacrimal canal dimensions did not vary significantly with age and weight. The small size of the studied population and the narrow range of weight in the selected rabbits prevent to make any assumption from this observation. As discussed above, it seems intuitive that the dimensions, especially the length of the lacrimal canal and of the lacrimal duct may vary according to breed, head conformity and the size of the rabbits. The impact of parameters, such as breed, ear-carriage type and weight, on lacrimal canal dimensions should be assessed in a larger group of healthy rabbits of different breeds and a wider range of weight.

The catheterization of the lacrimal punctum with a cannula is an essential step to perform a CT-DCG. Unsuccessful complete cannulating of the NLDS with suture material in rabbits with nasolacrimal obstruc-

Table 2. Dimensions of the different segments of the contrast filled NLDS (values in $\mathbf{m m} \pm$ SD).

$\begin{array}{ll}\text { Segment A } & \\ \text { Orbital segment } & 0.7 \pm 0.1 \\ \text { Canaliculus: maximum diameter } & 2.6 \pm 0.5 \\ \text { Lacrimal sac: maximum diameter } & 1.6 \pm 0.3 \\ \text { Intra-foraminal duct: maximum diameter } & \end{array}$

Segment B

Caudal maxillary narrowing (duct bend): minimum diameter

$0.6 \pm 0.1$

\section{Segment C}

Straight segment of the duct:

Length

DV and LL diameters

- caudal aspect

- mid-length

- rostral aspect

DV

$1.2 \pm 0.3$

$1.5 \pm 0.3$

$1.7 \pm 0.5$
$16.5 \pm 1.6$

LL

$0.9 \pm 0.2$

$1.2 \pm 0.3$

$1.4 \pm 0.3$

\section{Segment D}

Rostral incisor narrowing (duct bend): minimum diameter

$0.5 \pm 0.1$

\section{Segment E}

Rostral tubular segment (duct): DV and LL diameters

DV

$1.1 \pm 0.3$
LL

$0.7 \pm 0.2$

Segment F

Rostral membranous segment (duct): maximum diameter

$0.8 \pm 0.1$ 
tion or in normal rabbits has been reported (Burling et al., 1991). It has been suggested that the inability to successfully cannulate the entire NLDS could be due to some features of the anatomy of the NLDS in the rabbit and particularly narrowing and bending sites. In the present study (on healthy living rabbits), catheterization of the lacrimal punctum was felt to be an easy and fast procedure and no failure was encountered. Additionally, flushing the NLDS while filling it with iodinated contrast medium was easily performed in all 16 NLDS and was considered to indicate a proper patency of NLDS. The authors therefore consider that the failure to inject iodinated contrast medium into the NLDS should lead to a suspicion of NLDS obstruction.

In previously published studies, it has been suggested to inject $1 \mathrm{ml}$ of iodinated contrast medium for an optimal visualization of the NLDS in pet rabbits on radiographic dacryocystography (Marini et al., 1996). In the present study, 0.5 to $1 \mathrm{ml}$ of half-strength water-soluble iodinated contrast medium with $300 \mathrm{mgI} /$ $\mathrm{mL}$ as initial concentration was confirmed to provide an adequate filling and a proper visualization of the entire NLDS in CT-DCG. Some authors suggest to inject a smaller volume of contrast medium ( 0.3 to $0.5 \mathrm{ml}$ ) in order to prevent inhalation and contrast medium leakage and superimposition over anatomical structures on radiographic images (Jekl, 2016). With a maximum volume of $1 \mathrm{ml}$ of contrast medium injected in the NLDS, a visual check of contrast leakage at the nares, and the use of a cross-sectional modality (CT), excess amount of contrast medium out of the NLDS was not a concern in the present study. In order to obtain images of good diagnostic quality, injection of air into the NLDS should be avoided by filling the cannula with contrast medium before catheterization. The cannula should be removed before CT-DCG acquisition is performed to allow better visualization of the orbital segment of the NLDS.

In the present study, NLDS in healthy rabbits appears on CT-DCG as a continuous contrast-filled tubular structure with high variability in diameter through its entire length that exhibits two sharp bends with abrupt narrowing corresponding to the caudal maxillary bend and the rostral incisor bend of the lacrimal duct. CT-DCG allows accurate measurements of the NLDS diameter in healthy rabbits. It has provided anatomical features of the normal NLDS similar to those published in an anatomical study using injection of latex in the NLDS of rabbit cadavers (Burling et al., 1991).

Filling of both right and left NLDS with contrast medium was performed in all rabbits and was followed by a unique acquisition of CT-DCG images providing bilateral CT-DCG. No difference in the degree of filling was observed between the right and the left NLDS, indicating that the side (right versus left) being catheterized and injected first should not have any influence on image quality. Considering that catheterization and filling of the NLDS are easy to perform and not much time-consuming, it might be worth performing bilateral CT-DCG with a unique post-injection acquisition, especially when the clinical signs are unilateral as the sound side may provide normal reference images.

The present study was performed on clinically healthy adult rabbits aged between two and six years. A younger population of rabbits could have been selected for a study describing normal features. However, most of the rabbits presented at the authors' institution with clinical signs related to NLDS diseases, are adults. The authors found it thus more relevant to select adult rather than young rabbits for describing the normal appearance of the NLDS. A larger population could also have been selected, particularly for providing reference values of the NLDS in healthy rabbits. However, owners rarely ask for a screening head CT of their healthy rabbit. The owners of the rabbits selected for the present study were all members of the Exotics Department Team of ADVETIA Veterinary Hospital and were concerned about subclinical dental disease of their own rabbit. For ethical reasons, it was not possible to select a larger population of healthy rabbits.

Although normal CT-images were mandatory for inclusion in the study, mild increased density of the dental structures was allowed, as far as no tooth reverse overgrowth or tooth deformity was observed, and the hypodense 'apex' was still visualized. The oldest rabbit (six years old) was the only rabbit presenting a faintly increased density of the reserve crown with a reduced size of the hypodense apex in most jugal teeth. Neither signs of tooth reverse overgrowth or deformity, nor changes in peridental bony structures were observed leading the authors to conclude to non-pathological age-related changes and to select this rabbit for the study.

Computed tomography is an accurate modality to evaluate small-sized mineral-density structures. Therefore, CT and CT-DCG were expected to provide a detailed depiction of the thin-walled lacrimal canal and the contrast medium-filled NLDS in rabbits. A potential limit of the present study could have been an insufficient spatial resolution of the acquisition system considering the very small size of nasolacrimal structures in pet rabbits. Cone-beam CT is an imaging modality of choice for dental imaging in rabbits due to its high spatial resolution (Riggs et al., 2016 and 2017) and may also be helpful for the evaluation of the osseous structures of the lacrimal canal; however, to the authors' knowledge, it has not been evaluated and a major limitation of this imaging modality would be its poor contrast resolution for the evaluation of the soft tissue structures of the lacrimal duct.

Another limitation of the present descriptive study is that windowing and leveling changes made by the reader could slightly influence the measurements, especially the diameter and short axis dimensions. The 
authors chose to inject half-strength contrast medium solution in the NLDS for the description of normal features with this technique, but the dimensions might as well have slightly been influenced by contrast concentration.

In a very recent retrospective study about $\mathrm{CT}$ findings of dental disease in domestic rabbits, the authors have reported $17 \%$ (17 of 100 rabbits) with 'apparent' lacrimal canal lysis or obstruction in the studied population of rabbits affected with dental disease (Artiles et al., 2020), but the criteria of obstruction, as CT-dacryocystography was not performed, is not mentioned in this study. In rabbits with an obstructive NLDS disease, CT-DCG might help to identify the site and the cause of obstruction, such as external compression (pathological backward overgrowth, bony lesion, extranasolacrymal mass), mural lesion (developmental, hyperplastic or fibrotic duct stenosis) and intraluminal lesion (intra-ductal pus or dacryolith). In a recent study, CT-DCG performed in rabbits with experimentally induced dacryocystitis exhibited abnormal findings, such as incomplete filling of the NLDS and dilation of the NLDS segment proximal to the site of stenosis (Hou et al., 2017).

\section{CONCLUSION}

In the present study, it is indicated that CT-DCG can be easily performed in pet rabbits. A feasible and simple protocol is proposed and the normal features of the lacrimal canal and nasolacrimal drainage system in healthy dwarf rabbits are described.

As a next step, CT-DCG should be performed on rabbits with clinical signs of NLDS obstruction in order to assess its accuracy in discriminating the different causes of nasolacrimal obstruction.

\section{ACKNOWLEDGMENTS}

The authors would like to acknowledge Dr Kristina Burling, who gave the courtesy of the reproduction of her drawings.

Parts of this study were presented as an oral short communication at the EVDI annual meeting, 2019, Basel, Switzerland.

\section{REFERENCES}

Ansari, S.A., Pak, J., Shields, M. (2005). Pathology and imaging of the lacrimal drainage system. Neuroimaging Clinical of North America 15, 221-237.

Artiles, C.A., Sanchez-Migallon Guzman, D., Beaufrère, H., Philips, K.L. (2020). Computed tomographic findings of dental disease in domestic rabbits (Oryctolagus cuniculus): 100 cases (2009-2017). Journal of American Veterinary Medicine Association 257, 313-327.

Burling, K., Murphy, C.J., Da Silva Curiel, J., Koblick, P.,
Bellhorn, R.W. (1991). Anatomy of the rabbit nasolacrimal duct and its clinical implications. Veterinary Comparative Ophthalmology 1, 33-40.

Capello, V., Cauduro, A. (2008). Clinical technique: application of computed tomography for diagnosis of dental disease in the rabbit, guinea pig and chinchilla. Journal of Exotic Pets Medicine 17, 93-101.

Cleary, O.B., Easley, J.T., Henriksen, M.L., Brooks. D.E. (2011). Purulent dacryocystitis (nasolacrimal duct drainage) secondary to periapical tooth root infection in a donkey. Equine Veterinary Education 23, 553-558.

De Rycke, L.M., Boone, M.N., Van Caelenberg, A.I., Dierick, M., Van Hoorebeke, L., Van Bree, H., Gielen, I.M. (2012) Micro-computed tomography of the head and dentition in cadavers of clinically normal rabbits. American Journal of Veterinary Research 73, 227-232

Fishman, E.K., Ney, D.R., Heath, D.G., Corl, F.M., Horton, K.M., Johnson, P.T. (2006). Volume rendering versus maximum intensity projection in CT angiography: What Works Best, when, and why. Radiographics 26, 905-922.

Florin, M., Rusanen, E., Haessig, M., Richter, M., Spiess, B.M. (2009). Clinical presentation, treatment and outcome of dacryocystitis in rabbits: a retrospective study of 28 cases (2003-2007). Veterinary Ophthalmology 12, 350-356.

Freitag, S.K., Woog, J.J., Kousoubris, P.D., Curtin, H.D. (2002). Helical computed tomography dacryocystography with three dimensional reconstruction: a new view of the lacrimal drainage system. Ophthalmologic Plastic and Reconstructive Surgery 18, 121-132.

Hou, K., Ai, T., Liu, R., Xiang, N., Jin, J., Hu, W., Luo, B. (2017). Modeling chronic dacryocystitis in rabbits by nasolacrimal duct obstruction with self-curing resin. Journal of Ophtalmology, doi: 10.1155/2017/3438041

Janssen, A.G., Mansour, K., Bos, J.J., Castelijns, J.A. (2001). Diameter of the bony lacrimal canal: assessment with CT. American Journal of Neuroradiology 22, 845850.

Jekl V. (2016). Principles of radiography. In: HarcourtBrown F. and Chitty J. (editors). BSAVA Manual of Rabbit Dentistry, Surgery and Imaging, pp 51.

Liu, R., Li, H., Ai, T., Hu, W., Luo, B., Xiang, N. (2018). Pathological changes of the nasolacrimal duct in rabbit models of chronic dacryocystitis: correlation with lacrimal endoscopic findings. Graefe's Archive for Clinical and Experimental Ophtalmology. doi:10.1007/s00417018-4129-z

Manso-Diaz, G., Garcia-Lopez, J.M., Lopez-Sanroman, J., Teymans, O. (2018). Magnetic resonance dacryocystography in the horse: a feasibility study. Veterinary Ophtalmology 23, 129-134.

Marini, R.P., Charmaine, J.F., Kersten, D., Batchelder, M., Kaser, W., Li, X. (1996). Microbiologic, radiographic, and anatomic study of the nasolacrimal duct apparatus in the rabbit (Oryctolagus cuniculus). Laboratory Animal Science 46, 656-662.

Nöller, C., Henninger, W., Grönemeyer, W., Hirschberg, R.M., Budras, K.D. (2006). Computed tomography-anatomy of the normal feline nasolacrimal drainage system. Veterinary Radiology and Ultrasound 47, 53-60.

Nykamp, S.G., Scrivani, P.V., Pease, A.P. (2004). Computed tomography dacryocystography evaluation of the nasolacrimal apparatus. Veterinary Radiology and Ultrasound 45, 23-28.

Rached, P.A., Canola, J.C., Schlüter, C., Laus, J.L., Oech- 
tering, G., De Almeida, D.E., Ludewig, E. (2011). Computed tomographic-dacryocystography (CT-DCG) of the normal canine nasolacrimal drainage system with threedimensional reconstruction. Veterinary Ophthalmology 14, 174-179.

Rehorek, S.J., Holland, J.R., Johnson, J.L., Caprez, J.M., Cray, J., Mooney, M.P., Hillenius, W.J., Smith, T.D.(2011). Development of the lacrimal apparatus in the rabbit (Octyolagus cuniculus) and its potential role as an animal model for humans. Anatomy Research International 88,1-13.

Riggs, G.G., Arzi, B., Cissell, D.D., Hatcher, D.C., Kaas, P.H., Zhen, A., Verstraete, F.J.M. (2016). Clinical application of cone-beam computed tomography of the rabbit head: part 1 normal dentition. Frontiers in Veterinary Science 3, 93.

Riggs, G.G., Arzi, B., Cissell, D.D., Hatcher, D.C., Kaas, P.H., Zhen, A., Verstraete, F.J.M. (2017). Clinical application of cone-beam computed tomography of the rabbit head : part 2 dental disease. Frontiers in Veterinary Science 4, 5.

Schlueter, C., Budras K.D., Ludewig, E., Mayrhofer, E., Koenig, H.E., Walter, A., et al. (2009). CT and anatomi- cal study of the relationship between head conformation and the nasolacrimal drainage system. Journal of Feline Medicine and Surgery 11, 891-900.

Van Caelenberg, A.I., De Rycke, L.M., Hermans, K., Verhaert, L., Van Bree, H.J., Gielen, I.M. (2010). Computed tomography and cross-sectional anatomy of the head in healthy rabbits. American Journal of Veterinary Research 71, 293-303.

Van Caelenberg, A.I., De Rycke, L.M., Verhaert, L., Van Bree, H.J., Gielen, I.M. (2011a). Comparison of radiography and CT to identify changes in the skulls of four rabbits with dental disease. Journal of Veterinary Dentistry 28, 172-181.

Van Caelenberg, A.I., De Rycke, L.M., Hermans, K., Verhaert, L., Van Bree, H.J., Gielen, I.M. (2011b). Low-field magnetic resonance imaging and cross-sectional anatomy of the rabbit head. The Veterinary Journal 188, 83-91.

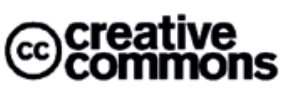

C 2020 by the authors. Licensee Vlaams Diergeneeskundig Tijdschrift, Ghent University, Belgium. This article is an open access article distributed under the terms and conditions of the Creative Commons Attribution (CC BY) license (http://creativecommons.org/licenses/by/4.0/).

\section{Paardenkerkhof van Childerik in Doornik}

De Salische Franken, een tak van de Frankische Germanen, veroverden bij de val van het Romeinse rijk onze streken en vestigden hun hoofdplaats in Doornik. Hun koning Childerik werd er begraven met onvoorstelbare rijkdom. Daarvan getuigen niet enkel de zogenaamde 'schat van Childerik', maar ook een massagraf met niet minder dan 21 paardenskeletten. C14-dateringen lieten toe dit 'paardenkerkhof' te situeren in de tijd van Childerik. De dieren waren begraven in drie holten in de rots gehouwen ongeveer twintig meter van het graf van de koning zelf.

Een dergelijk paardenkerkhof was uitzonderlijk bij de westelijke Germanen. Het getuigt van het aanzien, dat zowel paarden als Childerik zelf genoten. Zijn zoon Clovis (Chlodovich, Ludovik, Lodewijk, Ludwig, Louis) zou het kleine rijk uitbreiden over heel Frankrijk (het rijk van de Franken) tot in het noorden van Spanje en over een groot gedeelte van het huidige Duitsland.

Een opstelling in het archeologisch museum van Doornik geeft daar een beeld van weer. 